\title{
Embroidery as method: Stitching together narrative becomings and data
}

\section{Tamara S. Hancock}

College of Veterinary Medicine, Department of Veterinary Pathobiology, University of Missouri, Columbia, United States

hancockts@missouri.edu

https://orcid.org/0000-0002-6453-6248

(Received: 16 September 2019; accepted: 3 December 2019)

\section{Abstract}

There has been a shift in gender for the veterinary medical profession, with little attention paid to the affects of women becoming veterinary students. To interrogate women becoming-veterinarians, I tell stories of becomingveterinarian with a story of becoming-scholar, using narrative inquiry. I used data produced with current veterinary students in conversation with a photograph of a whiteboard and me. I embarked on an inventive analysis of sorting data excerpts and producing a new "white coat" with them-embroidering participant quotes onto the white coat I received when I entered veterinary school. This intra-action produced insights about becoming and I (re)present the crystallisation of these analyses into narratives of becoming stitched together. In this story, I interrogate my role and pose questions about learning and becoming.

Keywords: identity, becoming, narrative, embroidery, veterinarian

\section{Introduction}

Our subjectivities are "always constructed and stitched together imperfectly." (Haraway, 1991, as quoted in Alvermann, 2001, p. 130)

Mental health is of paramount concern in the veterinary profession. The suicide rate of veterinarians is greater than that of the general population in many countries, including the United Kingdom (Bartram \& Baldwin, 2010), United States (Tomasi et al., 2019; Witte, Spitzer, Edwards, Fowler, \& Nett, 2019), Australia, and Norway (Reisbig et al., 2012). For example, veterinarians who are men aged between 45 and 64 years have a relative risk (RR) of suicide 5.62 times higher than that of the general population (Bartram \& Baldwin, 2010). This risk is higher than dentists, pharmacists, and other medical practitioners. Most alarming is that veterinarians who are women have the highest relative risk $(R R=7.62)$ when compared with other non-veterinarian women and, moreover, this risk is significantly higher 
than in physicians who are women $(\mathrm{RR}=4.54)$. Recent studies have indicated that $34 \%$ of veterinary students in North America experience clinical levels of depression, and just over half of those students reported that their symptoms made it very to extremely difficult to perform routine tasks such as taking care of things at home (Karaffa \& Hancock, 2019). Other research revealed similar findings with student populations in Australia (Yang, Ward, \& Fawcett, 2019). Yang et al. (2019) reported 53.2\% of veterinary student respondents having high or very high scores on a measure of psychological distress, notably much higher than medical students (22.1\%), practicing veterinarians (14\%), or the general population (11.7\%). Both Yang, Ward, and Fawcett (2019) and Karaffa and Hancock (2019) reported that women have significantly higher levels of distress.

Contemporary research makes clear women in the veterinary profession are disproportionately affected by depression and depressive symptoms, and this warrants further investigation. Yet, quantitative descriptions fall short of providing more robust understandings of the lived experiences of women in the veterinary profession. Context is vital to grasp the reality of the lived experience. Irvine and Vermilya (2010) explained facets of the gender work in veterinary medicine, the most feminised of the health professions. Their study revealed that although the profession has become numerically dominated by women, it "remains gendered masculine" (p. 58). In their study of veterinarians who are women, Irvine and Vermilya (2010) identified that many of their participants were drawn to veterinary medicine because it capitalised on their natural talents of being caring and compassionate. Indeed, an influx of women into the profession occurred alongside a new philosophical emphasis of bond-centred practice where the focus of veterinary medical practice was on "importance of the human-animal relationship and the status of companion animals as friends and family members" (p. 65). This philosophical shift necessitated the need for emotional work in the profession and accordingly, the veterinarian now "becomes responsible not only for the medical care of the animal patient, but also for the emotional well-being of the human client" (Irvine and Vermilya, 2010, p. 65).

The culture of veterinary medicine does not typically rationalise emotional work in recruitment and training, nor does it monitise it in practice- "the cost of treatment is the same regardless of the veterinarian's concern for the client's emotional state" (Irvine \& Vermilya, 2010, p. 65). The veterinary profession "capitalizes on the 'invisible work' that many women veterinarians may see as a 'natural' expression of who they are" (Irvine and Vermilya, 2010, p. 65); yet, at the same time, women must remain in control of their emotions as "a necessary part of presenting a professional image" (p. 67). Indeed, these competing discourses of competence and caring are well established in medical education literature that seeks to understand professional identity (MacLeod, 2011). The uneven focus on these discourses in professional socialisation was affirmed by medical students who emphasised the centrality of technical and scientific development over caring, the latter positioned as something "nice to do, but not the "true basis" of medicine" (MacLeod, 2011, p. 380). In sum, medical professions require women to manage this dual identity in developing professional identities, in becoming-veterinarian. 
In medical practices, the materials available and the authority ascribed to them-antibiotics, muzzles and chutes, stethoscopes, white coats, protocols-fundamentally shape both practice and knowledge (Fenwick, 2014). Fenwick (2014) asserted that "context may be critical, but to understand context simply as an abstract container is to miss the turmoil of relationships among these myriad non-human as well as human elements that shape, moment to moment, particular dynamics of context" (p. 46). With this in mind, many scholars have called into question the conventional metaphors that represent teaching/learning, where knowledge is "acquired" and transferred by individuals (see Fenwick, 2014; Fenwick \& Dahlgren, 2015; McMurtry \& McMurtry, 2016; McMurtry, Rohse, \& Kilgour, 2016; Soffer, 2016). Instead, these scholars offered an alternative: sociomaterial theories. These theories can attend to "learning in terms of collective dynamics, participation in social communities and active engagement with material contexts" (McMurtry et al., 2016, p. 169). McMurtry et al. (2016) cautioned that sociomaterial theories may at first seem counterintuitive partly due to the tenacity of the conventional notions of knowledge, which position isolated individuals acquiring knowledge against a backdrop of social dynamics and materials. Instead, sociomaterial theories look beyond this backdrop, highlighting how learning and doing is inseparable from its fabric. This necessitates recognition that "our solitary standpoint is limited and that embracing another's viewpoint is essential to our own" (Sousanis, 2015, p. $38)$.

Veterinary medicine has disproportionate numbers of women practitioners and students who suffer disproportionately from depressive symptoms and are at greater risk for completing suicide. Therefore, additional scholarly work is necessary to open up the nature of women's experiences. In particular, research that can trace the learning and doing, the becomingveterinarian, as threads interwoven among a social-cultural-material fabric.

\section{Becoming}

Becoming is a theoretical concept that positions the development of professional identities as ongoing, contingent, and co-constituted by human and nonhuman matter (Barad, 2003, 2007). Barad $(2003,2007)$ advanced a posthumanist (sociomaterial) theory of performativity that built on the work of scholars, such as Judith Butler (1990), who have worked to develop poststructural theories of gender performativity. Butler (1990) claimed gender is not something we are bestowed-we never get to "be," but are always in the process of becoming through our performances that constitute and contest the gendered subject produced as an effect. Performativity is the repeated stylisations that are performed and congeal over time, and which produce the (gendered) subject within rigid norms.

Barad (2007) positioned the material elements as agentic alongside humans. In her words, "all bodies, not merely 'human' bodies, come to matter through the world's iterative intraactivity-its performativity” (Barad, 2007, p. 152). Materials and humans/discursive practices co-produce enactments of agency, where one portion of the assemblage is not privileged over the other. Agency is an enactment momentarily borne from the intra-action of 
material, nonmaterial, and discursive practices. In this way material $\Leftrightarrow$ discursive, ${ }^{1}$ and one does not precede the other-they are always already (re)producing each other. Therefore, becoming has no definite beginning or end. It is momentary, produced through materialdiscursive practices that differentially and dynamically produce/contest the boundaries of performance and agential intra-action (Barad, 2007, p. 141). In Barad's $(2003,2007)$ theory of agential realism, intra-actions produce a multiplicity of differential becomings.

The process of becoming is complex and "rather than merely acting professionally, medical students are expected to become professionals and to embody a suitable professional identity" (Monrouxe, Rees, \& Hu, 2011, p. 586). MacLeod (2011) used discourse as a theoretical and analytical tool to explore the development of professional identities in medical students-the process of becoming-doctor-using discourses of competence and caring. Discourses of competence referred to technical aspects of medicine, of knowledge and skills, of knowing the right answers or having the facts. On the other hand, discourses of caring focused on the social aspects of medicine-nontechnical dimensions that may address issues of gender, race, class, or family status, for example. MacLeod's (2011) findings affirmed the complex and competitive nature of these discourses, and how discourses of competence tended to be a central concern throughout negotiations embedded within the process of becoming-doctors.

\section{Reflexivity/diffraction}

In the writing that follows, I trace a few threads of becoming-veterinarians from a photoelicitation project with women veterinary students. In that project, the innovative methodological process of producing a material white coat embellished with embroidered data and reflexive journaling/memoing were synergistic. "Reflexive," in a literal sense, is "of, relating to, characterized by, or being a relation that exists between an entity and itself" ("Reflexive," n.d.). However, more often than not in qualitative research, reflexivity is a "generalized practice in which researchers attempt to acknowledge their influence on research" (Bozalek \& Zembylas, 2017, p. 115). The use of reflexivity arises out of positivist critiques of qualitative research that suggest practices of reflexivity could "increase transparency and trustworthiness in research" (Bozalek \& Zembylas, 2017, p. 115).

Diffraction is a similar research practice and the term is derived from Barad's (2007) conceptualisation of difference in the entanglements of matter and meaning. Borrowed from quantum physics, diffraction is where waves combine when they overlap and produce different waveforms - waves that can be amplified, superimposed, and different (Bozalek \& Zembylas, 2017). While reflexivity is a practice of cutting apart the entangled apparatus of researcher/researched/data/materials, diffraction considers how this coming together of inquiry combines, intra-acts, and produces difference. In these ways, to be reflexive in this project was to engage in diffraction - to surface partial accounts of entanglements that produced insights inseparable from the fabric and needlework of these stories of becoming.

Some writing, and some of my writing, uses hyphens to indicate the entanglement, the intra-action between material and discursive. Here I use the double arrow when discussing the theory broadly and hyphens in (re)presenting what was produced when thinking with theory. See Jackson and Mazzei (2012, p. 110) for more. 
What follows next is focused on those methods and results of the diffractive aspects of this project stitched together with the matters of the photo-elicitation work. This work explored the following research questions: "How are women veterinary students becomingveterinarians?" "How am I, veterinarian-woman, becoming-scholar?" "How do our stories stitch together?" This scholarship is an intentional focus on the storied intersections of materials and discourse as they produced insights into the complexity of differential becoming (veterinarian) that hides behind the taken-for-granted, material (re)presentations of cultural norms.

\section{Method/ology}

\section{Narrative inquiry}

Engagement with Barad's $(2003,2007)$ theory of becoming insists that "our narratives play a part in constituting the relation between the past, present, and future" (Rosiek \& Snyder, 2018 , p. 3). Narratives emerge with, in, and are of the research process and this produces the possibilities for new becomings. "Narrative, as becoming, displaces the concept of 'understanding' and 'experience' of the other (there is no such subject) or on meaning (since this is always in flux), but on practicing/doing/performing/being in the dance of connectivity and intra-action" (Munro-Hendry, Mitchell, \& Eaton, 2018, p. 11).

(Re)presenting narratives involves mutual co-constructions of storied data collages in and of historical, social, material, and cultural traditions. These stories are small "[co-]constructed realities in the process of interactions ... dialogues" (Moen, 2006, p. 5) and intra-actions (Barad, 2003, 2007). Intra-actions denote the coming together and mutual agency of all matter, human and non-human. Altogether, "the storyteller does not tell the story so much as [they] are told by it" (Andrews, Squire, \& Tamboukou, 2012, p. 4). "The narrating process co-constitutes the writer, reader, and focus of study" (Rosiek \& Snyder, 2018, p. 7). Tamboukou (2012) described narratives as agents that trace the possibilities of becomings for women that cannot be separated from the processes that produced them, and used genealogy with archival data to meticulously trace the complexities and paradoxes of women's becomings (see Tamboukou, 1999, 2000, 2008, 2010, 2012). In these ways, stories that focus on the seemingly mundane activities of daily life provide tracings of the complex and antagonistic caring/competent veterinary becomings.

The clothes we wear are as much a part of our stories as uttered words or the words refused, inhabiting our silences. The white coat is a material symbol of medical authority and power. It traces an "asymmetry that derives from educational, technical, social, and economic differences between physicians and patients" (Wear, 1998, p. 735). The white coat also is said to represent the "pureness" of a profession, having origins in the late 19th century when the "value of cleanliness and antisepsis was firmly fixed as the core of medical science" (Goldberg, 2008, p. 311). Yet, to students, white coats are the material subject of white coat ceremonies, rituals that demarcate the formal inclusion into a profession and those duties and privileges nested within this new belonging. When donned, a student is expected to embody 
the identity of doctor. What does it mean to be a doctor? Is "doctor" a definable identity, or a fluid space of becoming, or both/and?

Narrative inquiry desires a method to "work meticulously ... looking for insignificant details, bringing . . . light [to] unthought-of contours of various ways, discourses and practices" (Tamboukou, 2012, p. 88). (Re)presenting narratives requires mechanisms to problematise the discursive privilege of authorship and question the simplicity implied in certain (re)presentations. Next, I trace narrative entanglements, and what diffracted with and in the materialised narrative inquiry, and situate these possibilities among those produced for those I researched with.

\section{Narrative entanglements}

As a woman, a veterinarian, and a specialist who has been entrenched in various veterinary schools over the past 10 years, I have become curious about the nature of the profession. I've endured training programmes, packaged my feelings away (through necessity), lost friendships, almost lost my marriage, but also gained a lot in the process. Along the way, I've found myself wondering, who am I performing for and why? I ask these questions as a scholar: "Who am I performing for, why, and how?"

My time in veterinary school was challenging-personally, academically. Yet, I don't think I was depressed. I had friends who were. Classmates were open and vocal about it. Perhaps I didn't even notice if I was-becoming-veterinarian was supposed to be hard. I lost my first colleague to suicide during my second year out of veterinary school. I noticed a facebook post that morning about "doing what I needed to do:'-( "and I glibly thought it was about euthanising a pet or patient. It was not. I grieved this loss in multiplicities. I still grieve.

I came to this college of veterinary medicine (CVM) as a resident of clinical pathology and master's student in veterinary pathobiology. For some of the students, I was a teacher in one of their first-year courses and, for others, they may have interacted with and come to know me over the summer at the freshman orientation programme. Otherwise, students may know me from interactions on the veterinary medicine campus, or from messages I have sent promoting programmes for teaching and curriculum work. This narrative environment, the $\mathrm{CVM}$, is nested in a larger professional narrative environment: the profession of veterinary medicine.

I remained at this university as a doctoral student in the college of education and, during that time, I became a mother and worked hard to perform as if everything was okay. I wondered if a professional woman-mother could actually be successful? Was I being selfish to have a child and if so, were the crippling effects of motherhood my wake-up call to this reality? One summer, I came across a whiteboard in a student study room at the CVM and snapped a picture of it (Figure 1). For me, it produced many questions. What was happening? Who owns these words? Whose story does it depict, and is it mine to tell? Is it mine to use? This image moved people and I felt that by finding it, the entanglement desired me-and I hope I am worthy of the desiring and the stories it produces. 


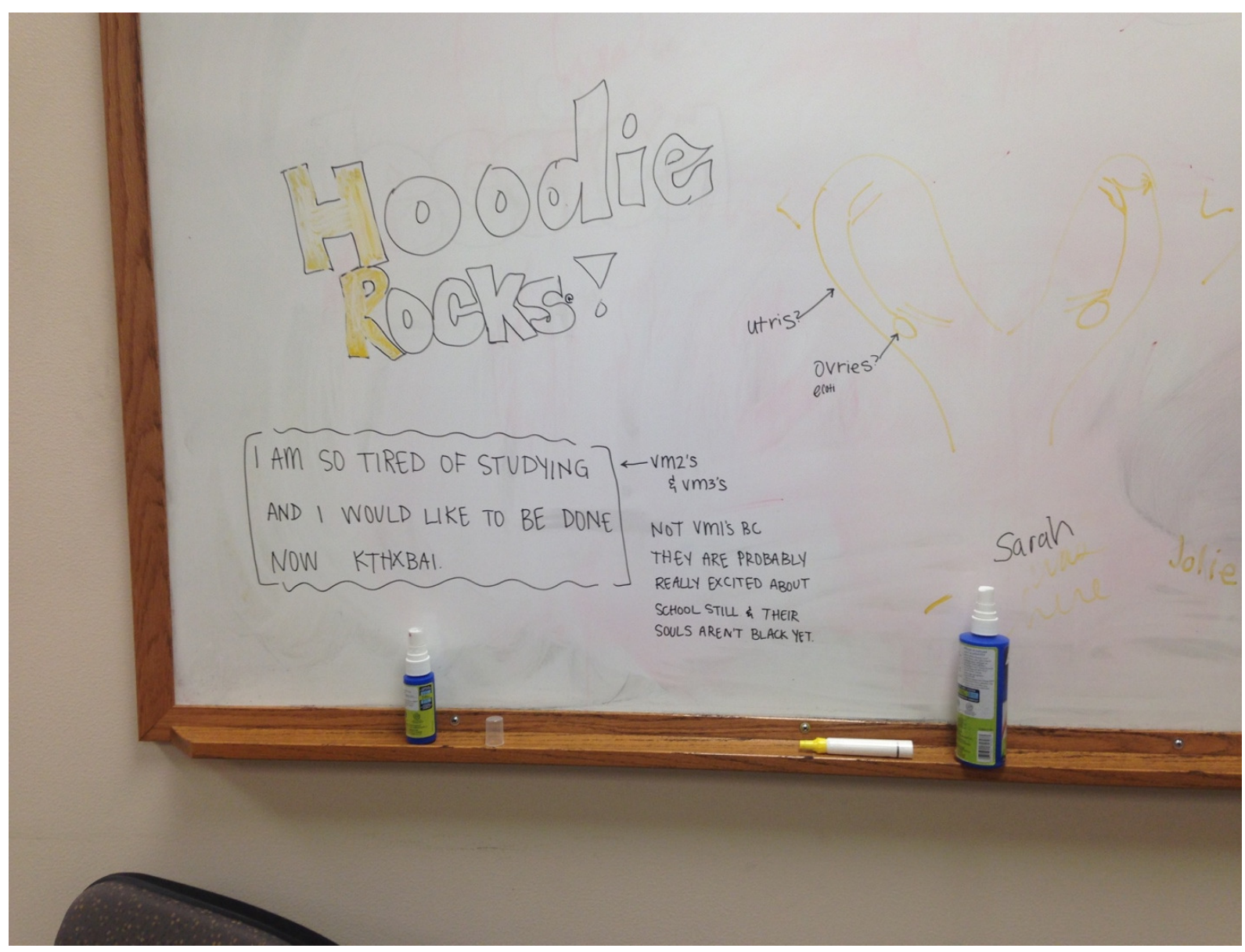

Figure 1: Whiteboard image used in photo-elicitation discussions

\section{Data production}

Students were recruited to participate in a research project centred on the material image of the whiteboard (Figure 1). Emails that recruited for focus groups with peers were sent to each of the preclinical classes. The message stated the research was about student well-being, curriculum, and would be stories and conversations about a whiteboard. Additionally, informed consent with further information about the study was attached and given again prior to the recorded sessions. Four women consented to participate, three of whom were third-year students, Georgia, Sylvie, and Caroline; one was a second-year student, Alicia (all pseudonyms). The focus group and interviews lasted 30 minutes to one hour, and were semistructured around the image captured of the whiteboard.

These conversations were conducted in a small study room in the veterinary medicine campus. In this space, I tried to maintain a friendly connection with the students by making small talk about coursework, shared experiences, or seemingly trivial matters of the day (e.g., the weather). Despite this - my attempts to dress casually and emphasise that I was not after any particular/right responses, just those stories they might tell around the whiteboard-I often found myself uncomfortable. I wrote of this in my memos. For instance, after my session with Alicia I wrote, “Tamara-Olympus² produces a tension. What are my worries?” I

2 Olympus was the brand of audio-recorder I was using as one way to produce a record of these conversations. 
felt that Tamara-Olympus evoked thoughts of particular ways to be in interview spaces: particular ways to be a researcher. With a focus on an endpoint-to-come, my performances felt shameful, inadequate. Perhaps the students and I both felt as though our performances would never be enough, and wondered if the other would notice.

\section{Narrative needlework}

Focus groups and interview recordings were transcribed verbatim. I sorted and aggregated utterances and sections of transcripts that operationalised discourses of caring or competence and placed these excerpts into a table with labelled columns (i.e., "caring" and "competence"). Within this analysis, an additional category, "inside," emerged. This category referred to the hidden interior of a white coat, where the white coat represents the enactment of professional identities - the (discursive) performance of identity. To don the white coat represents the performativity of normalised skills, knowledge, and personas to "be" a professional. The inside consisted of utterances that referred to dark, personal, or hidden aspects of a path traversed through the structured professional curriculum.

These categorical aggregates of quotes or longer stretches of speech were printed onto white paper and cut into smaller pieces so that each data excerpt was on one small slip of paper. These slips of paper, these utterances and data excerpts, were kept with their dimensions: caring, competence, or inside. To engage in narrative as becoming (Munro-Hendry et al., 2018) the slips of paper were embroidered onto my personal white coat awarded at my college's white coat ceremony. My white coat symbolically welcomed me to the veterinary profession and the performative expectations therein. This methodologic step also produced a literal white coat with data. A white coat to don in the ways that showcase competence and caring - and hide what is on the inside. This parallels the work of Weber (2005) who worked with shoes as a metaphor, a mode of inquiry, and a normative device of (gendered) performance.

These material and metaphorical intra-actions produced creative insights and enabled synthesis of these data, my own imbrication. From this synthesis, I produced a first-person fictional narrative of becoming-veterinarian. Fiction was used as a tool to (re)present the complex nature of the veterinary school experience (Leavy, 2013) and within this effort to portray realness is an effort to reach an audience beyond that of other scholars. Fiction permits the use of creative writing techniques and literary tools that are not typically a part of the discourse of social science research (Leavy, 2013). Throughout the embroidery, I maintained a diffractive journal of what was produced and, in doing so, I traced my becoming-with-others: becoming-veterinarian and becoming-scholar.

\section{Narrative becomings}

In this section, I showcase these first-person narratives, side by side. This move is akin to the dialogic give-and-take Hamilton (2005) employed in her self-study where she wrote herself in analytic conversation with Winslow Homer, a long-deceased artist. The duality this device might impress upon the reader should be interpreted with caution. Although to place my 
narrative becoming alongside the fictitious student narrative becoming does not create a hierarchy of one over another, it does generate a false boundary between them. The nature of our narrative becomings - that they are entangled and not easy to separate-is difficult to (re)present. The side-by-side presentation below-presenting them stitched together-is my attempt to provide minor justice to this issue of (re)presentation and authorship. I conclude these becomings with the methodologic, metaphoric, and material white coat.

\section{Becoming-veterinarian}

You know, I almost changed my mind before I got here. Getting a 17 on my first organic chemistry test in undergrad almost made me quit. Luckily, I got to drop one exam score-my professor was awesome - and so that didn't stand in my way. Looking back, I wonder if I should have seen it as a wakeup call; it was actually easy in undergrad, but I thought I was stressed out then. HA! I had perfect grades. I did all sorts of extra stuff. I actually had a balanced life. Then came vet school. You get to anatomy, and physiology, and microanatomy, and neurology and suddenly you're not making As anymore, you're making Cs. And I don't feel like I have any time to devote to friendships and relationships. You know, my husband and I only saw each other for dinner and then I'd be studying, and we just never saw each other, and it was really rough . . . it still is kind of rough. Sometimes it can feel better, but you know, once I'm here I can't give up. I guess I feel sort of trapped. I can't back out now.

Someone once told me, "as long as you're still here you deserve to be here," and I try to remember that but it's not always easy. I've had this reality check recently after going home for winter break. I was visiting with friends and family and like they're all excited for me, they think I'm

\section{Becoming-scholar}

\section{Tuesday.}

The needlework is hard. I only have two quotes sewn on and I'm wondering if I bit off more than I can chew. When I found my white coat from my white coat ceremony-when I started vet school in 2007-it was in the basement. At least it was hanging up. ${ }^{3} \mathrm{I}^{\prime} \mathrm{m}$ equivalently surprised how well it's held up-I wore it in the anatomy lab for all of first year, I'm sure it's radiating something that causes cancer. It was neglected while I was a resident because I got a new coat with my name, Dr. Hancock, on it. It has some stains that don't make any sense to me. Rust? They seem to emanate and radiate - the fabric in these areas has a different texture.

I definitely don't feel like I know what I'm doing and at the same time, I feel like I know what I'm doing. My husband asked, "what is that?" To which I replied, "it's research."

The narrative project, in general, has taken over. My evenings after my child goes to sleep are spent reading, writing, or doing needlework. I can't stop thinking about it a lot of the time. I've been doing yoga, running more - that clears my mind. It helps, truly.

I don't know what other people will

I find curious, the place and care of the various material entanglements of social status/identities. For comparison, my wedding dress is still shoved haphazardly into a moving box from the move from Indiana to Iowa 10 years ago. I feel more committed to my marriage than my profession from a personal standpoint. From a scholarly perspective, I feel more committed to unpacking and (re)imagining my profession. 
awesome, and are asking, "Oh, are you going to do a residency and specialise?!" So, I explain the internship and residency process to them and then have to admit, you know, I'm not going to do it because I don't want to, but even more, if I wanted to I don't have the grades or grade point average (GPA) - the cumulative average of all my final grades where 4.0 is perfect. It's common knowledge that you need at least a 3.0 or above for even just externships. One of our professors was saying that when they are evaluating candidates for internships or residencies, they separate them out, putting the 4.0 to 3.5 in one pile, and the 3.4 to 3.0 in another, and then everyone else over here. Then they start with the highest GPAs, then the middle, and they may not even get to the lower GPAs even though everybody is a doctor. I'm not good enough to be a specialist and definitely not good enough to be in academia. What's even harder to communicate to my family and friends is, even though I'm already halfway through the entire curriculum, I could still fail out. They think, well, you're already halfway through and you're not going to fail anything. There's this expectation out there and this expectation in me. I don't knowit's really heavy. Although it was kind of a joke first year, "oh I'm going to fail out of this class or that class," the further we get the more real it gets in more ways than one. I' $m$ in the last semester before clinics and thinking about starting over at the beginningnope. Just nope.

The curriculum is hard. I mean, obviously it should be, it's doctor school, right? Some people can't wait for clinics, but me, I'm terrified. I feel like I have no idea. I legit feel like I don't know anything. I worry I'm going to kill something. All I've been doing think. I didn't even share the true nature of my fiction project with my advisor. I was worried I would scare him.

Seriously. Doing the hard work and then shutting up about it, having a smile and appearing unflappable, flawlessbeing a good woman. I've got that down. It's hauntingly comfortable.

\section{Wednesday.}

I just finished my caring quotes. It's so weird to wonder how this will all come together when I think, or thought I knew going into it, what it might look like. I'm enjoying the small parts of this. Using my creative license to make the stitches however I please. When I started, I thought I wanted to use suture or staples. Medical materials. I didn't have any around and thought about how it's not medicine that attaches this discourse, these utterances, but creative license to constitutively produce. Plus, why not try to make the most out of something_-visually intriguing materials that extend beyond the words.

My fingertips hurt. This is hard work.

When I chose the colours of needlework floss, I wanted to show the two halves of caring and competence and, then, what was produced, the inside of the coat - the people who are (not) present ought to be a blend of these two. I spent a lot of time thinking about these colours - what might they mean? What and why did I choose what I chose? After much deliberation, I arrived at conceptualising through primary and secondary colours. Two halves make a new whole. So, yellow and red (primary) halves, when mixed would produce an orange (secondary). The colours that I chose to reflect what is produced are not always orange, or show the influence of other colours, other elements of becoming. The outcomes of difference should not be a 
for two years is looking at PowerPoint slides and I feel like we don't get any help learning how to behave like a doctor-or, I guess, even think like a doctor, either. It's not only understanding all the processes and all the information, it's now "what are you going to do?" and "how are you going to present it to the client?" and then "what happens if money is an issue?" and how do I even figure out the cheapest methods to do anything - to find a solution? And then, how do I act confident when I don't know? How do I handle my first euthanasia? What do I say? How do I reassure them? What's not appropriate? How do I deal with angry clients? Or people who just want rabies shots but aren't going to treat the ear infection? Will I even have health insurance at the clinic I work at, or be able to work full time? What about my student loans? The unknown, the darkness, it's-it's never-ending. I don't know. I guess I'm trying to reconcile that hopefully getting to do what I think I love is worth it. I guess, since I'm still here I belong here, right?

We lost two students during second year. They were more mental health type issues; I think just the stresses of school did them in. I'm thinking the class below us will probably have some that need to drop out as well. You know how we get paired up with "little siblings" when the underclassmen start? My little sib dropped and so did my friends' littles. It all just adds up and . . - you can't handle it anymore. I try to attend family events when I can, but it's hard. It's something I have to be willing to take a hit for and sometimes I can't take that hit. I'm usually studying while I'm there, anyways. It's nice when professors understand that you have a lot going on. That they acknowledge you're working hard because when they don't it feels like it's not enough. One surprise, or are they? Although not intended, when I felt confident about my floss lot and was heading to the checkout, it dawned on me that my primary colours were those of my DVM alma mater: cardinal and gold. The colours that line my veterinary doctoral hood.

Did I mention my fingers hurt? Hurts to type and I didn't really realise that it was painful until I started to type. To reflect, and write out my experiences. Huh. That's some food for thought.

When I was nearly finished with the caring needlework, I realised I had sewed the front and the back of the coat together. It's not the worst mistake but what I am surprised by is how I didn't notice when it was happening. I was nearly finished stitching on the next slip of paper when I noticed. At first, I was pissed. How could I have missed that? I thought I was being reasonably careful and checking every so often to make sure I didn't do this one thing-sew the coat together. Sigh. I pondered how I might "fix it" and "make it better" and while pondering, I became aware of what it was I was doing. I was rejecting the becoming of this human-material assemblage - the uniqueness of the trajectory. The coat could still work, but it might be a bit more awkward or uncomfortable if donned-specifically if donned in ways that (re)produce the original expectation of what it means to have or be a "good" fit. How many deviations from the expectations are labelled defective? Unworkable?

Needing to be fixed or made better? What does this look like when we're talking about students or colleagues?

I need to stitch on.

I feel like in some ways my stitches are getting sloppy and in others, they're getting better. I'm finding that a lot of 
of our professors for an 8 o'clock class said, "you know, if you don't want to show up this will be on Tegrity," that's like recording things and posting it online. That really takes the pressure off. It's nice to have that permission to be human. You know, but even that is hard-being a like a person, you know. I feel changed. Even when I'm visiting friends on break, trying to relax, and a friend of a friend came to our barbeque with her Boxer. Making small talk I asked her how old she was, what her name was, etcetera, and then the woman says, "oh and so you're a vet student, so she's got this lump on her head ... " Immediately all I can think is: mast cell tumour or, how this old Boxer is probably gonna die of cancer in the next two years. How do I go about talking about that without sounding insensitive? Like, I can't even see a cute puppy or kitten without thinking about the problems they're going to grow up with and die from. We're trained in these first two years, "here's all the problems" and you can't unthink that. I don't know how to relate to real people and relax, and my brain needs that. It's rough but like, I can't turn off what I know now. I don't know how to be normal again. I want to feel normal or, I guess, at least happy. embroidery is planning your next move while you make your current stitch/move. I tried my hand at knotsthere are two types: Colonial and French. I tried both and failed miserably. I tried to make it look like a bow, like it was on purpose. Who knows?

I've been telling myself that the little mistakes are happy accidents. Like Bob Ross, the soft-spoken American painter ans television icon, suggested (Ross, 2017). The imperfect stitches are interesting and mean more. Are more. I don't know what, yet.

\section{Thursday.}

While working on the white coat tonight I had a blanket ${ }^{4}$ on my lap to keep me warm and cozy. I stitched my blanket to the coat. I know I had previously decided to let the happy mistakes live on but I had caught this one immediately. With meticulous attention, I unthreaded the stitch back out of the coat. From there, I realised that it didn't pierce full thickness through the blanket, so I made some small cuts to pull the thread clean from its partial blanket encasement. I pondered how I worked to keep myself warm and cozy, and couldn't keep this simple feeling or need separate from this project.

\section{Monday.}

This is a work in progress and not my final product. But then again, isn't that what we all are?

I present to you the empty white coat of veterinarians (Figures $2 \& 3$ ). 

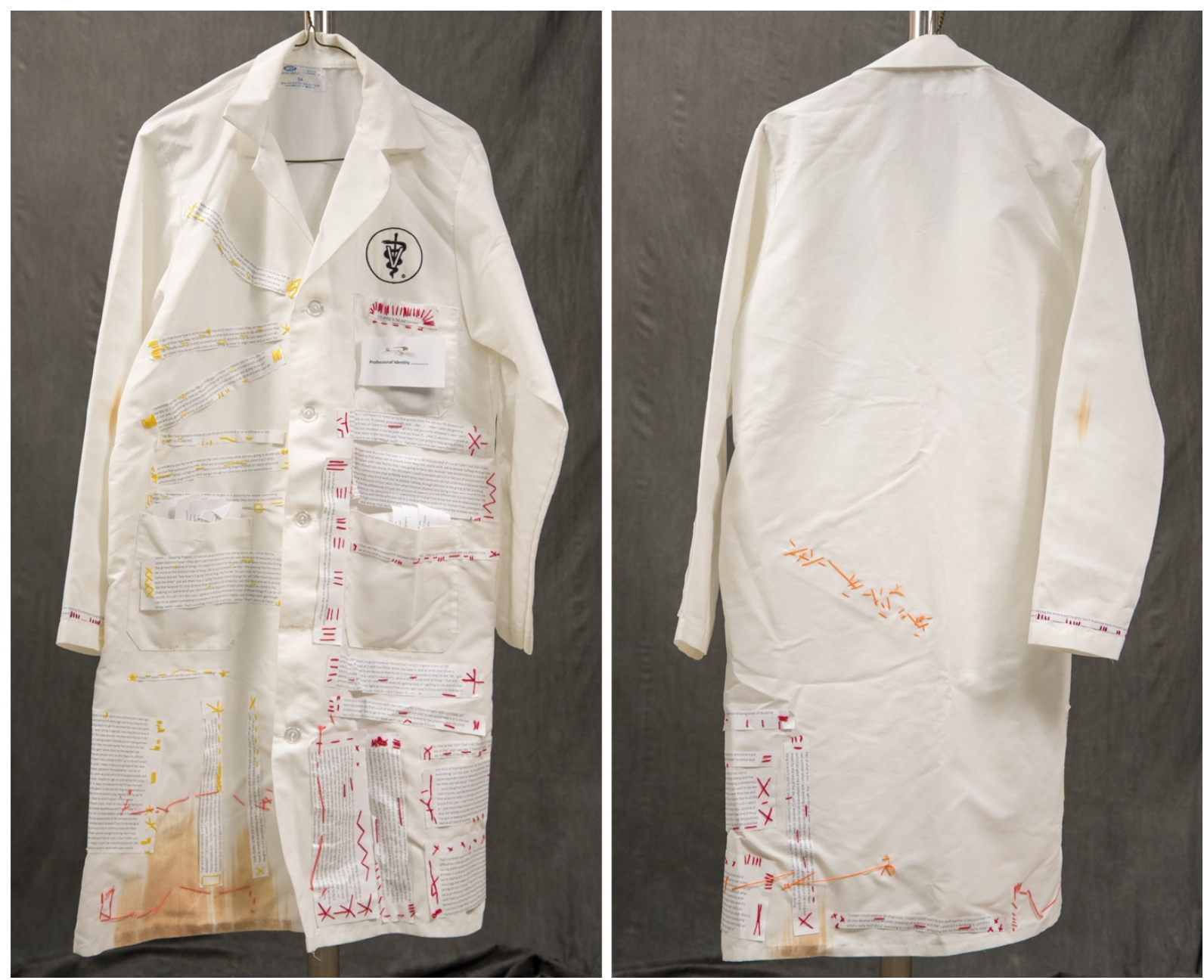

Figure 2: The embroidered and empty white coat of veterinarians. The left panel depicts the front, and the right panel depicts the back. Not pictured: A mirrored compact in the pocket near the heart, which invites a new intra-action with the white coat as matter and method and metaphor. What is produced when we (do not) see our entangled selves?

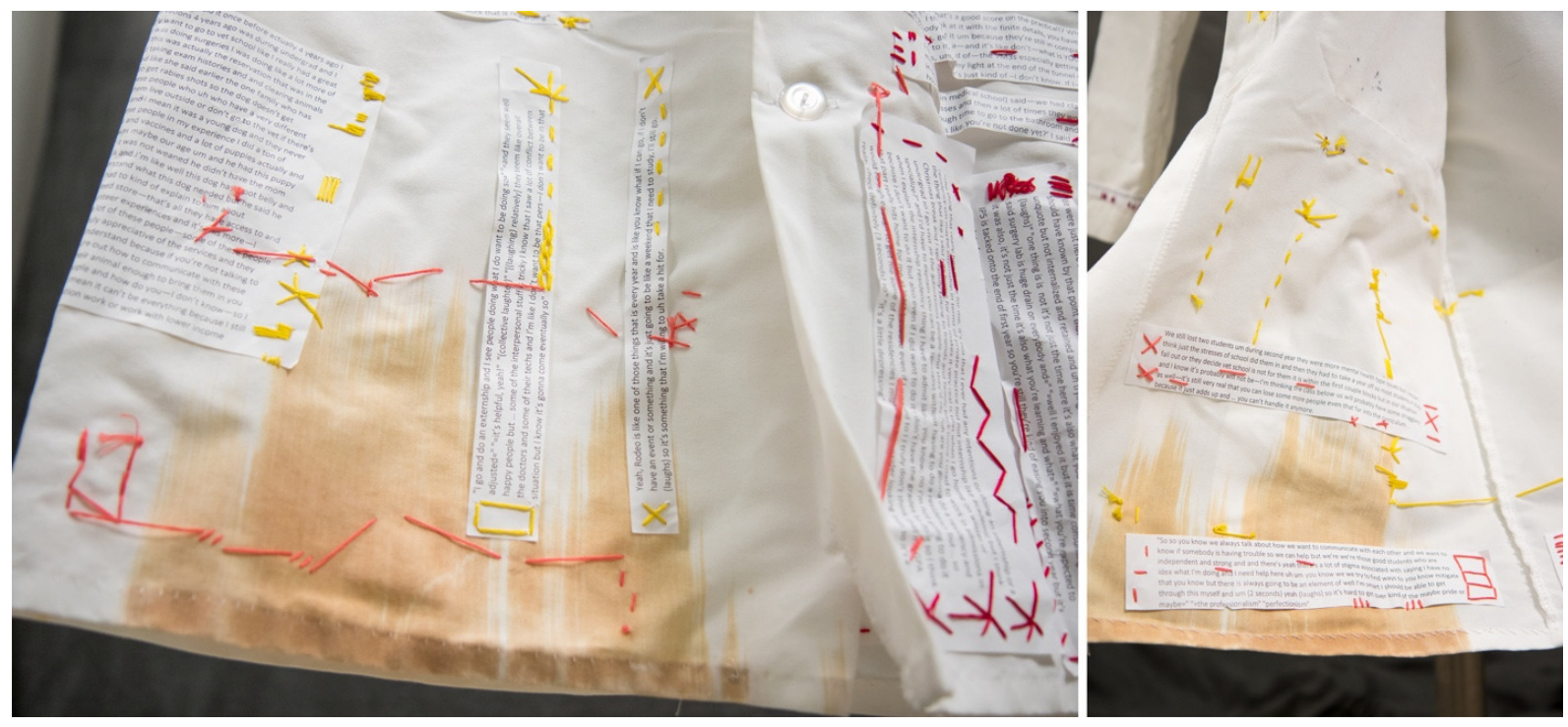

Figure 3: Select details of the embroidered and empty white coat of veterinarians. This image depicts stains of unknown origin, embroidered performativity. The two sides of this panel depict what is visible on the outside and what is inside. 


\section{Scholarly impressions}

“Thank you for noticing the whiteboard [laughs] I don't know how many clinicians actually try to focus on the whiteboard" (Georgia, focus group). This focus (group) was different than others, and Georgia noticed. Our constellation of entanglements produced momentary gratitude. In medicine, we talk of constellations of signs that produce diagnoses or those conditions for the generation of certain pathologies. In this constellation of narratives, what else is produced?

Connections of differential becoming were produced in how each of us struggled with, and in the complexity and uncertainty of, our becomings. We wondered what our becomings- the socialisations we were willingly immersed within — were doing with us, much as Pithouse (2005) wondered about what her "privileged school experiences" were doing with her (p. 207). The fictional veterinary student grappled with competing performances of competence in terms of grades and knowledge and caring for herself, friends, and new animal companions in her life. Though these internal tensions were shared by the students I discussed the whiteboard with, they were ones I identified with. They were and are a part of my becomingscholar as much as they were and are a part of my becoming-veterinarian. They are our narratives - how knowing/being/doing our becomings are unstable and unknowable, and how we grapple with this flux and this flux grapples with us. The veterinary student feels changed and cannot unthink all the problems and, at the same time, I am preoccupied with the physical pain of my becoming-scholar - of producing a white coat through embroidery while this white coat produces us.

The insights produced from my needlework and embroidery were the most surprising dimension of this work. I had not expected these intra-actions to affect me in the ways they did, and how producing this is producing me. The details of using my own coat, the stains of my coat, and embroidery floss selections held space for me to become so much of my own becoming-scholar. The accidents were some of the most insightful areas in ways in which the departure from the expected, the subversions of performativity, produced awareness in and of the departure from a norm. The pull of a rigid adherence to "the way," rather than a way is curious and something our becomings grappled with differently. In other scholarship, I write of grappling with the myriad entanglements of becoming-scholar and the theoretical concepts that sustain my work (Hancock \& Fontanella-Nothom, 2020). How we notice the pressures of the material-discursive world pressing against and forming us in those moments that the moulds fracture. These entanglements fractured the moulds of becoming for these students, this composite student, and me in ways we were and are uncertain about.

The order in which I chose to embroider-working first on caring and competence before attending to those inner elements of becoming, the inside. This made visible the notion that what was stitched inside is ma(r)king what is and can be performatively professional. Furthermore, in the work with caring, the stitches accidentally collapsed the fullness of the coat and this has implications for what could "fill" or "fit" the coat, impacting how a professional identity could be donned given the nature of caring. For me, my caring for my 
child now made my performativity increasingly difficult-it was and is more complex than I imagined. In the ways in which it made me interrogate my own internalised misogynycould a successful professional woman also be a mother? In the ways in which it made me feel crumpled and imperfect and how I need(ed) to work on accepting what is becoming. This struggle parallels some of those described by medical students, where discourses of competence have influenced them "to the point where [they] are pressured to demonstrate professional identities consistent with discourses of competence at the expense of raising other concerns" (MacLeod, 2011, p. 390). This raises other concerns: of believing I am now less than-because I am raising others.

My agential cut to free the floss from my blanket when they were accidentally sewn together was a generative moment. I noticed my "mistake" immediately and decided to unthread my veterinary attachments from my scholarly attachments. This departure was more than physical, it was ontological, epistemological, and literal. Becoming-scholar for me was a paradigm shift. It is a turn from the positivist tradition of biomedical science to (post)qualitative social science. I have embraced an interpretivist and "post" stance on research, and I position my work to interrogate and unsettle the taken-for-granted assumptions of my professions.

This work affirms that intra-action with the curriculum produces hardship for some. More work is needed to examine the extent to which our curricula, both hidden and explicit, are integral pieces of the crisis of mental illness and suicide in our profession. Indeed, veterinary school is and will be hard. Transitions in life are hard. Are blackened souls a necessary rite of passage? Are they the calluses our fingers form so that we do not feel the pain of needlework? How might these stories effect changes in classroom and curricular practices? Should they?

More broadly, consider the words of Khalil Gibran to conclude (as quoted in Sousanis, 2015).

Your children are not your children.

They are the sons and daughters of life's longing for itself. ...

You are the bows from which your children

As living arrows are sent forth (p. 139)

Putting these words in conversation with this research produces new thoughts. There are so many factors, so many possibilities for differential becoming, we are but the bows from which our graduates, as living arrows, are sent forth. Our policies permit and prohibit arrows from being taken up, included in quivers (cohorts of matriculating students), placed and subsequently launched forth (leaping over or circumnavigating hurdles on the way to graduation). We need not to look to our targets (outcomes) but to acknowledge them and their entanglement as we craft our bows. Knowing that arrows, in becoming, never truly land and 
self-reflexive or diffractive methodologies hold so much promise for interrogation of these possible trajectories of becoming.

\section{References}

Alvermann, D. E. (2001). Narrative approaches. In M. L. Kamil, P. B. Mosenthal, P. D. Pearson, \& R. Barr (Eds.), Methods of literacy research (Vol. 3). New York, NY: Routledge.

Andrews, M., Squire, C., \& Tamboukou, M. (2012). What is narrative research? In M. Andrews, C. Squire, \& M. Tamboukou (Eds.), Doing narrative research (2 ed., pp. 126). Thousand Oaks, CA: SAGE.

Barad, K. (2003). Posthumanist performativity: Toward an understanding of how matter comes to matter. Journal of Women in Culture and Society, 28(3), 801-831.

Barad, K. (2007). Meeting the universe halfway: Quantum physics and the entanglement of matter and meaning. Durham, NC: Duke University Press.

Bartram, D. J., \& Baldwin, D. S. (2010). Veterinary surgeons and suicide: A structured review of possible influences on increased risk. The Veterinary Record, 166(13), 388397. doi:10.1136/vr.b4794

Bozalek, V., \& Zembylas, M. (2017). Diffraction or reflection? Sketching the contours of two methodologies in educational research. International Journal of Qualitative Studies in Education, 30(2), 111-127. doi:10.1080/09518398.2016.1201166

Butler, J. (1990). Gender trouble. New York, NY: Routledge.

Fenwick, T. (2014). Sociomateriality in medical practice and learning: Attuning to what matters. Medical Education, 48(1), 44-52. doi:10.1111/medu.12295

Fenwick, T., \& Dahlgren, M. A. (2015). Towards socio-material approaches in simulationbased education: Lessons from complexity theory. Medical Education, 49(4), 359367. doi:10.1111/medu. 12638

Goldberg, J. L. (2008). Humanism or professionalism? The white coat ceremony and medical education. Academic Medicine, 83(8), 715-722.

Hamilton, M. L. (2005). Using pictures at an exhibition to explore my teaching practices. In C. Mitchell, S. Weber, \& K. O'Reilly-Scanlon (Eds.), Just who do we think we are? Methodologies for autobiography and self-study in teaching (pp. 58-68). New York, NY: RoutledgeFalmer. 
Hancock, T. S., \& Fontanella-Nothom, O. (2020). Becoming with/in flux: Pedagogies of sustainment (POSt). Qualitative Inquiry, 26(1), 81-88.

doi:10.1177/1077800419874827

Irvine, L., \& Vermilya, J. R. (2010). Gender work in a feminized profession: The case of veterinary medicine. Gender \& Society, 24(1), 56-82.

doi:10.1177/0891243209355978

Jackson, A. Y., \& Mazzei, L. A. (2012). Thinking with theory in qualitative research: Viewing data across multiple perspectives (1st ed.). New York, NY: Routledge.

Karaffa, K. M., \& Hancock, T. S. (2019). Mental health experiences and service use among veterinary medical students. Journal of Veterinary Medical Education, 46(4), 449458. doi:10.3138/jvme.1017-145r1

Leavy, P. (2013). Fiction as research practice: Short stories, novellas, and novels. Walnut Creek, CA: Left Coast Press.

MacLeod, A. (2011). Caring, competence and professional identities in medical education. Advances in Health Sciences Education, 16, 375-394.

McMurtry, A., \& McMurtry, R. Y. (2016). More productive ways to think about learning, knowledge and education. Medical Education, 50(11), 1091-1093. doi:10.1111/medu. 13070

McMurtry, A., Rohse, S., \& Kilgour, K. N. (2016). Socio-material perspectives on interprofessional team and collaborative learning. Medical Education, 50(2), 169180. doi:10.1111/medu. 12833

Moen, T. (2006). Reflections on the narrative research approach. International Journal of Qualitative Methods, 5(4), 1-11.

Monrouxe, L. V., Rees, C. E., \& Hu, W. (2011). Differences in medical students' explicit discourses of professionalism: Acting, representing, becoming. Medical Education, 45(6), 585-602. doi:10.1111/j.1365-2923.2010.03878.x

Munro-Hendry, P., Mitchell, R. W., \& Eaton, P. W. (2018). Troubling method: Narrative research as being. New York, NY: Peter Lang.

Pithouse, K. (2005). Self-study through narrative interpretation: Probing lived experiences of educational privilege. In C. Mitchell, S. Weber, \& K. O'Reilly-Scanlon (Eds.), Just who do we think we are? Methodologies for autobiography and self-study in teaching (pp. 206-217). New York, NY: RoutledgeFalmer.

Reflexive. (n.d.) In Merriam-Webster.com Dictionary. Retrieved from https://www.merriamwebster.com/dictionary/reflexive 
Reisbig, A. M. J., Danielson, J. A., Wu, T.-F., Hafen, M., Krienert, A., Girard, D., \& Garlock, J. (2012). A study of depression and anxiety, general health, and academic performance in three cohorts of veterinary medical students across the first three semesters of veterinary school. Journal of Veterinary Medical Education, 39(4), 341358. doi:10.3138/jvme.0712-065R

Rosiek, J. L., \& Snyder, J. (2018). Narrative inquiry and new materialism: Stories as (not necessarily benign) agents. Qualitative Inquiry, Online first, 1-12. doi:10.1177/1077800418784326

Ross, B. (2017). Happy little accidents: The wit and wisdom of Bob Ross (M. Witte, Ed.). Philadelphia, PA: Running Press.

Soffer, A. K. B. (2016). Situating beyond the social: Understanding the role of materiality in Danish nursing education. Advances in Health Sciences Education, 21(4), 819-832. doi:10.1007/s10459-016-9668-7

Sousanis, N. (2015). Unflattening. Cambridge, MA: Harvard University Press.

Tamboukou, M. (1999). Spacing herself: Women in education. Gender and Education, 11(2), 125-139. doi:10.1080/09540259920654

Tamboukou, M. (2000). The paradox of being a woman teacher. Gender and Education, 12(4), 463-478. doi:10.1080/09540250020004108

Tamboukou, M. (2008). Re-imagining the narratable subject. Qualitative Research, 8(3), 283-292. doi:10.1177/1468794106093623

Tamboukou, M. (2010). Broken narratives, visual forces. In M. Hyvärinen (Ed.), Beyond narrative coherence (Vol. 11). Philadephia, PA: John Benjamins Publishing.

Tamboukou, M. (2012). A Foucauldian approach to narratives. In M. Andrews, C. Squire, \& M. Tamboukou (Eds.), Doing narrative research (2nd ed.). Thousand Oaks, CA: SAGE.

Tomasi, S. E., Fechter-Leggett, E. D., Edwards, N. T., Reddish, A. D., Crosby, A. E., \& Nett, R. J. (2019). Suicide among veterinarians in the United States from 1979 through 2015. Journal of American Veterinary Medical Association, 254(1), 104-112.

Wear, D. (1998). On white coats and professional development: The formal and the hidden curricula. Annals of Internal Medicine, 129(9), 734-737. doi:10.7326/0003-4819-1299-199811010-00010

Weber, S. (2005). The pedagogy of shoes: Clothing and the body in self-study. In C. Mitchell, S. Weber, \& K. O'Reilly-Scanlon (Eds.), Just who do we think we are? Methodologies for autobiography and self-study in teaching (pp. 13-21). New York, NY: RoutledgeFalmer. 
Witte, T. K., Spitzer, E. G., Edwards, N., Fowler, K. A., \& Nett, R. J. (2019). Suicides and deaths of undetermined intent among veterinary professionals from 2003 to 2014. Journal of American Veterinary Medical Association, 255(5), 595-608.

Yang, H. H., Ward, M. P., \& Fawcett, A. (2019). DVM students report higher psychological distress than the Australian public, medical students, junior medical officers and practicing veterinarians. Australian Veterinary Journal, 97(10), 373-381.

doi:10.1111/avj.12845 